\title{
The effects of vibration on efficiency in off-road cyclists
}

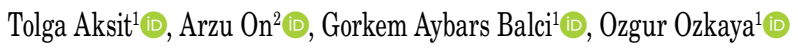 \\ ${ }^{1}$ Department of Coaching Education, Ege University, Faculty of Sport Sciences, Izmir, Turkey \\ ${ }^{2}$ Department of Physical Medicine and Rehabilitation, Ege University Faculty of Medicine, Izmir, Turkey
}

Received: October 01, 2019 Accepted: December 26, 2019 Published online: March 04, 2021

\begin{abstract}
Objectives: The aim of this study was to investigate whether vibration significantly affected the efficiency of off-road cyclists.

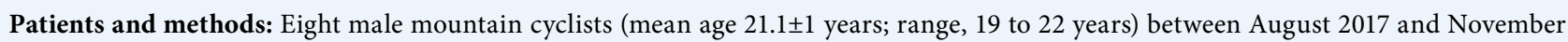
2017 were included. The experimental protocol included four testing sessions with a one-day interval between testing sessions: a familiarization session; performance of submaximal tests; performance of maximal graded exercise test; and a 30-min mountain bike trial performed with vibration or without vibration. Physiological measures including volume of oxygen uptake $\left(\mathrm{VO}_{2}\right)$, volume of carbon dioxide output $\left(\mathrm{VCO}_{2}\right), \mathrm{VO}_{2}, \mathrm{VCO}_{2}$, heart rate, respiratory exchange ratio, rating of perceived exertion, and gross efficiency (GE) were compared between the trials performed with vibration or without vibration.
\end{abstract}

Results: There was a significant increase in the GE with the addition of intermittent vibration, particularly over the last 15 min of the cycling trial $(\mathrm{p}<0.05)$. There were no significant effects of vibration on other parameters.

Conclusion: This study demonstrates that addition of intermittent vibration may provide positive benefits in improving GE during a 30-min submaximal cycling trial.

Keywords: Gross efficiency, mountain biking, oxygen uptake, performance, vibration.

Off-road cycling, also known as mountain biking (MTB), has become a popular recreational and professional biking activity worldwide. Performance in MTB is influenced by multiple factors including general anthropometric characteristics of cyclists, sport-specific skills, hand grip endurance, aerobic capacity, and anaerobic capacity to perform intermittent high-intensity bouts of cycling and overall self-confidence. ${ }^{[1]}$ The physiological demands of MTB differ from those of road biking in terms of riding techniques and the roughness of the terrain to be traversed. The demands of MTB performance, both across and within MTB categories (i.e., cross-country or hill climb/uphill), can substantially vary. ${ }^{[2]}$ These physiological demands must be exerted on the varying terrains on which
MTB races are held, which require skilled techniques (technical single-track and straight tracks), roads with rough surfaces including rocky areas, and natural barriers, which require fast descent and jumps. Impellizzeri and Marcora $^{[3]}$ reported that, across these various conditions, cyclists were continuously exposed to vibration.

Vibration affects neural factors of neuromuscular control, such as increased synchronization of motor units, potentiation of the stretch reflex, leading to an involuntary tonic vibration reflex, increased activity of synergistic muscles, and increased inhibition of antagonist muscles. ${ }^{[4]}$ Together, these vibration-induced effects on neuromuscular control produce acute beneficial effects on performance. ${ }^{[5]}$

Corresponding author: Arzu On, MD. Ege Üniversitesi Tıp Fakültesi Fiziksel Tip ve Rehabilitasyon Anabilim Dalı, 35100 Bornova, İzmir, Türkiye. e-mail: arzu.on@ege.edu.tr 
The mechanical stimulus of vibration is transmitted along the linked segments of the body, stimulating sensory receptors including muscle spindles. It has been also argued that this sensory stimulation is responsible for increasing the number of alpha motor neurons recruited for a movement and the strength of a muscle contraction by recruiting muscle fibrils, which were previously inactive, as well as improving the change in muscle length, particularly lengthening, through the effect of vibration on muscle spindles. ${ }^{[6]}$ Therefore, in response to vibration, the number of motor units participating in a movement increases and the muscle contraction becomes stronger, while muscles stretch more quickly. Thus, acute vibration leads to an increase in the strength and a better neuromuscular adaptation. ${ }^{[7,8]}$ In contrast to the positive benefits of acute exposure to vibration, the limited research evaluating long-term exposure to vibration has reported detrimental effects, including increased muscle fatigue and decreased muscle contraction strength. ${ }^{[9]}$

Although the vibration is inherent to MTB, due to the roughness of the off-road trails, very few studies on cycling have examined vibration exposure as an experimental variable. Review of the literature reveals only three studies including vibration in their experimental protocol, each reporting a significant increase in the volume of oxygen uptake $\left(\mathrm{VO}_{2}\right)$ during graded exercise testing performed with vibration, compared to a no-vibration condition. ${ }^{[10,11]}$ The economy of performance in off-road cyclists is defined as obtaining a high portion of energy by aerobic sources, when increased speed on rough-challenging tracks. This criterion of economy is important to include in physiological evaluation and performance determination of cyclists. ${ }^{[12]}$ The rate between the work generated and total metabolic energy cost is defined as gross efficiency (GE), where the GE is directly proportional to performance during long-term endurance exercise. However, to the best of our knowledge, the effect of whole-body vibration (WBV) on the GE in off-road cyclists has yet to be evaluated. In the present study, therefore, we hypothesized that exposure to intermittent WBV would increase GE and aimed to evaluate the effects WBV during cycling training of GE.

\section{PATIENTS AND METHODS}

This prospective study was conducted at Ege University, Faculty of Sport Sciences, Climatic Chamber Laboratory between August 2017 and November 2017. A total of eight healthy male mountain cyclists (mean age $21.1 \pm 1$ years; range, 19 to 22 years), three of whom were competitive cyclists in the national team, were included. All participants were trained a minimum of $8 \mathrm{~h}$ per week. Exclusion criteria were orthopedic problems, metabolic disorders, cardiovascular disease and age $<18$ years. A written informed consent was obtained from each participant. The study protocol was approved by the Ege University Medical Research Ethics Committee (15-9/13). The study was conducted in accordance with the principles of the Declaration of Helsinki. A repeated-measures design was used for the laboratory experiment. The participants were asked to refrain from strenuous exercise for at least one day prior to each testing session. The experimental protocol included four testing session, each performed in the laboratory setting with a one-day interval. Sessions were consisted of four steps: (i) familiarization session; (ii) submaximal performance tests; (iii) maximal graded exercise test; and (iv) two 30-min mountain bike trial performed with vibration $(\mathrm{VbX}+)$ and without vibration (VbX-). The study design is shown in Figure 1.

\section{Procedures}

\section{Familiarization sessions and submaximal incremental step test}

Familiarization sessions were performed to adapt participants to the equipment such as mask of gas analyzer, Peak Bike cycle ergometer, WBV platform, or test settings (VbX- and VbX+). Following the familiarization procedures, the submaximal test was initiated consisting of five 4-min bouts performed on a frictional braked Peak Bike cycle ergometer. The workload increases were set to 24 to 32 Watts for each athlete to ensure that each athlete could reach the cyclist's ventilatory threshold (VT) determined using a regression slope of the min ventilation (VE) versus $\mathrm{VO}_{2}$ production $\left(\mathrm{VE}-\mathrm{VO}_{2}\right)$ and using the slope of volume of carbon dioxide (VCO2) production and $\mathrm{O}_{2}$ utilization $\left(\mathrm{VCO}_{2}-\mathrm{VO}_{2}\right)$.

\section{Maximal graded exercise test}

Incremental tests were performed by 24 to 40 Watts increments every two min, from VT to volitional exhaustion. For the maximal incremental test, strong verbal encouragement was provided to participants throughout the tests to ensure maximal effort. The rating of perceived exertion (RPE) was recorded during the last $30 \mathrm{sec}$ of each two-min 


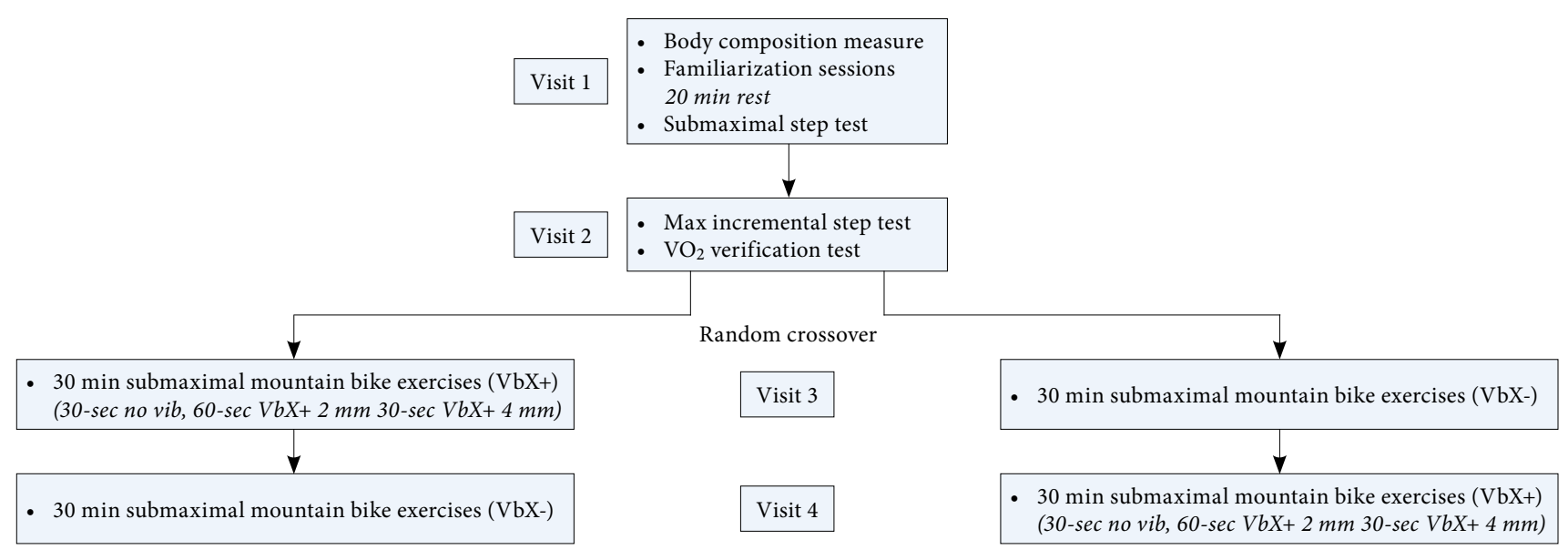

Figure 1. Schematic illustration of the experimental protocol. $\mathrm{VO}_{2}$ : Oxygen uptake; $\mathrm{VbX}+$ : With vibration; $\mathrm{VbX}$-: Without vibration.

stage, using 6 to 20 range of the Borg Scale. The highest average $\mathrm{VO}_{2}$ calculated over the last $30 \mathrm{sec}$ of each stage was considered as the peak oxygen consumption $\left(\mathrm{VO}_{2 \text { peak }}\right)$. Test termination criteria were as follows: (i) plateau $\left(<150 \mathrm{~mL} \cdot \mathrm{min}^{-1}\right.$ increase) in $\mathrm{VO}_{2}$; (ii) maximal heart rate $\left(\mathrm{HR}_{\max }\right) \geq 90 \%$ of the $\mathrm{HR}_{\max }$ predicted for age (220-age); (iii) RER $\geq 1.05$, and (iv) inability to maintain an rpm of 80 over a three-sec duration.

\section{Submaximal mountain bike trials}

The VbX- and VbX+ bouts were performed on a 26-inch aluminum front suspension mountain bike (585 Eagle, Italy) with an additional frictional resistance system (Beta Elastomer, Germany). The system was placed on a platform fixed onto the WBV equipment (Power Plate my3; Performance Health Systems, Northbrook, USA; Figure 2). Specific Power Plate intensities enabled vibration stimuli of $2 \mathrm{~mm}$ to $4 \mathrm{~mm}$ in amplitude, delivered at $35 \mathrm{~Hz}$. The $30-\mathrm{min}$ $\mathrm{VbX}+$ cycling bout was performed at the wattage corresponding to the VT. Exposure to VbX+ was provided over the last $15 \mathrm{~min}$ of the 30 -min cycling bout, and consisted of three sessions as follows: $30 \mathrm{sec} V b X-, 60 \mathrm{sec} \mathrm{VbX}+$ at $2 \mathrm{~mm}$, and $30 \mathrm{sec}$ $\mathrm{VbX}+$ at $4 \mathrm{~mm}$. In addition, a $30-\mathrm{min}$ VbX- bout was completed on the same platform. The cyclists were instructed to maintain a constant load with the wattage corresponding to $\mathrm{VO}_{2}$ of $60 \% \mathrm{VO}_{2 \text { peak }}$ at an $\mathrm{rpm}$ of 80 throughout the test. The seat height was adjusted to accommodate the rider's personal preferences. The wheel pressure was standardized at 70 PSI for all test sessions.

\section{Physiological measurements}

The $\mathrm{VO}_{2}, \mathrm{VCO}_{2}, \mathrm{VE}$, and RER were monitored, breath-by-breath during all tests, using a standard gas analyzer (Quark b2; Cosmed Srl., Rome, Italy). Data were smoothed over every five-point interval and interpolated every $30 \mathrm{sec}$ to eliminate outlying data. The $\mathrm{VO}_{2}\left(\mathrm{~mL} \cdot \mathrm{min}^{-1} \cdot \mathrm{kg}^{-1}\right)$ gas analyzer was calibrated according to the manufacturer's instruction. The HR was continuously recorded using a HR monitor system (Garmin EDGE 1000, Garmin International Inc., KS, USA). The GE (\%) was calculated as the ratio of mechanical power-to-metabolic power. Mechanical power $\left(\mathrm{P}_{\mathrm{mec}}\right)$ was evaluated from the wattage and the $\mathrm{rpm}$ (Eq.1), while metabolic power $\left(\mathrm{P}_{\mathrm{met}}\right)$ was

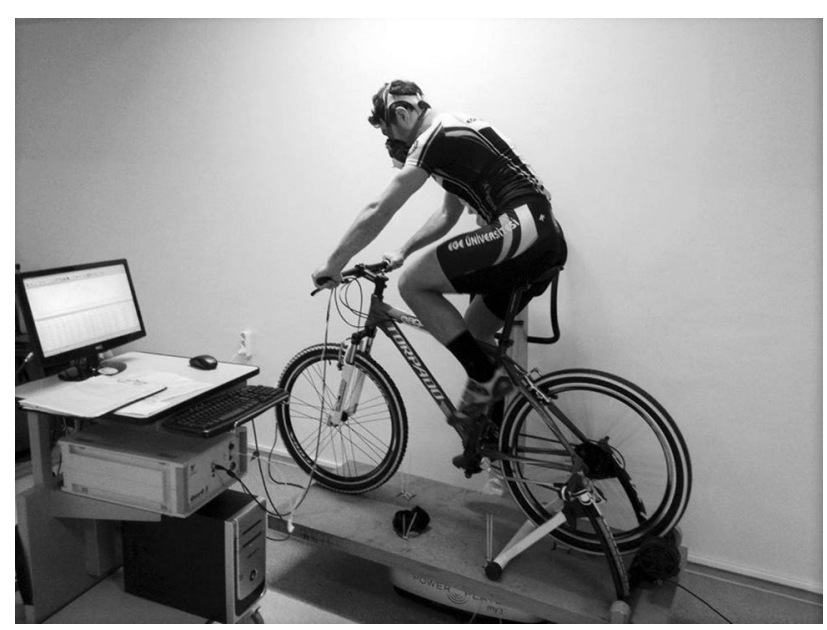

Figure 2. Placement of the system on a platform fixed to whole body vibration equipment. 
determined using average RER and $\mathrm{VO}_{2}$ values of the submaximal mountain bike trial (Eq.2). The GE\% was, then, calculated as the ratio of $P_{\text {met }}$ and $\mathrm{P}_{\text {mec }}$ with one-min intervals (Eq.3). To obtain a valid determination of muscular efficiency, oxygen consumption was measured at steady state.

Eq.1

$\mathrm{P}_{\text {mec }}=\operatorname{Load}(\mathrm{kg}) \times$ cadence $(\mathrm{rpm})$

Eq.2

$\mathrm{P}_{\text {met }}=4.94 \times \mathrm{RER}+16.04 / 60 \times \mathrm{VO}_{2}$

Eq.3

$\mathrm{GE}(\%)=\mathrm{P}_{\text {mec }} / \mathrm{P}_{\text {met }} \times 100$

The above mentioned physiological measures were collected and calculated as $\mathrm{VO}_{2}$ and $\mathrm{VCO}_{2}$ $\left(\mathrm{mL} \cdot \mathrm{min}^{-1} \cdot \mathrm{kg}^{-1}\right), \mathrm{VO}_{2}$ and $\mathrm{VCO}_{2}\left(\mathrm{~L} \cdot \mathrm{min}^{-1}\right), \mathrm{VE}\left(\mathrm{L} \cdot \mathrm{min}^{-1}\right)$, RER, HR, total energy expenditure (kcal), rpm, power output (watt), GE (\%), and RPE.

\section{Statistical analysis}

Sample size was calculated based on previous studies evaluating efficiency in cyclists. ${ }^{[13,14]}$ By taking eight individuals with an effect size and type 1 error rate of 0.90 and 0.05 respectively the study power was achieved as 0.72 . Statistical analysis was performed using the PASW version 18.0 software (SPSS Inc., Chicago, IL, USA). Descriptive data were expressed in mean \pm standard deviation, median (min-max), or number and frequency. Since the sample size was lower than 30, the Wilcoxon test was used to analyze $\mathrm{VO}_{2}, \mathrm{VCO}_{2}$, VE, RER, RPE, HR, and GE\% differences between the VbX+ and VbX- conditions. Relative reliability was analyzed by the intra-class correlation coefficient (ICC) and 95\% confidence interval (CI) was estimated with two-factor mixed-effect model with an absolute agreement. A $p$ value of $<0.05$ was considered statistically significant.

\section{RESULTS}

Of a total of eight male mountain cyclists, the mean height was $1.8 \pm 0.1 \mathrm{~m}$, the mean weight was $71.1 \pm 3.7 \mathrm{~kg}$, and the mean estimated body fat percentage was $10.4 \pm 1.9 \%$. Descriptive physiological characteristics and performance parameters are presented in Table 1. Differences in $\mathrm{VO}_{2}$ and GE\%, calculated during the 30-min submaximal mountain bike trials under $\mathrm{VbX}+$ and $\mathrm{VbX}$ - conditions, are shown in Figure 3.

The comparisons of the physiological and performance parameters during 30-min $\mathrm{VbX}+$ and VbX- are summarized in Table 2. There were no significant differences between the mean values of the physiological and performance variables at $\mathrm{VbX}+$ and VbX-. However, a significant difference in GE\% was observed between $\mathrm{VbX}+$ and $\mathrm{VbX}$ - conditions $(\mathrm{p}<0.05)$.

There was also a significant GE\% difference between the first 15-min and the last 15-min of the submaximal trials between the $\mathrm{VbX}+$ and VbX- exercises $(\mathrm{p}<0.05) \quad($ Table 3$)$. The mean $\mathrm{VO}_{2}$ value corresponding to $60 \%$ of $\mathrm{VO}_{2 \text { peak }}$ was $37.2 \pm 6.0 \mathrm{~mL} \cdot \mathrm{min}^{-1} \cdot \mathrm{kg}^{-1}$. The mean $\mathrm{VO}_{2}$ value over

TABLE 1

Peak physiological and performance responses during graded exercise test $(n=8)$

\begin{tabular}{|c|c|c|c|}
\hline & \multirow[b]{2}{*}{ Mean \pm SD } & \multirow[b]{2}{*}{ Min-Max } & \multirow{2}{*}{$\begin{array}{c}95 \% \text { CI } \\
\text { Lower-Upper }\end{array}$} \\
\hline & & & \\
\hline $\mathrm{VO}_{2}\left(\mathrm{~mL} \cdot \mathrm{min}^{-1} \cdot \mathrm{kg}^{-1}\right)$ & $61.2 \pm 3.5$ & $49.0-78.21$ & $52.91-64.40$ \\
\hline $\mathrm{VO}_{2}\left(\mathrm{~L} \cdot \mathrm{min}^{-1}\right)$ & $4.3 \pm 0.2$ & $3.51-4.97$ & $3.89-4.66$ \\
\hline $\mathrm{P}_{\text {peak }}(\mathrm{W})$ & $348.1 \pm 18.5$ & $277.0-426$ & 304.29-391.95 \\
\hline Respiratory exchange ratio & $1.1 \pm 0.0$ & $1.0-1.20$ & $1.01-1.13$ \\
\hline Heart rate $(\mathrm{bpm})$ & $191.8 \pm 3.2$ & $178.0-202$ & $184.22-199.27$ \\
\hline Minute ventilation $\left(\mathrm{L} \cdot \mathrm{min}^{-1}\right)$ & $165.9 \pm 6.8$ & 134.42-199 & 149.77-182 \\
\hline $\mathrm{VCO}_{2}\left(\mathrm{~L} \cdot \mathrm{min}^{-1}\right)$ & $4.6 \pm 0.2$ & $3.65-5.27$ & $3.98-5.11$ \\
\hline Rating of perceived exertion (Borg scale) & $19 \pm 0.4$ & $17.0-20.0$ & $18.10-19.89$ \\
\hline Time to exhaustion (s) & $478.9 \pm 31.6$ & $390.0-641.0$ & 404.19-553.55 \\
\hline
\end{tabular}


(a)

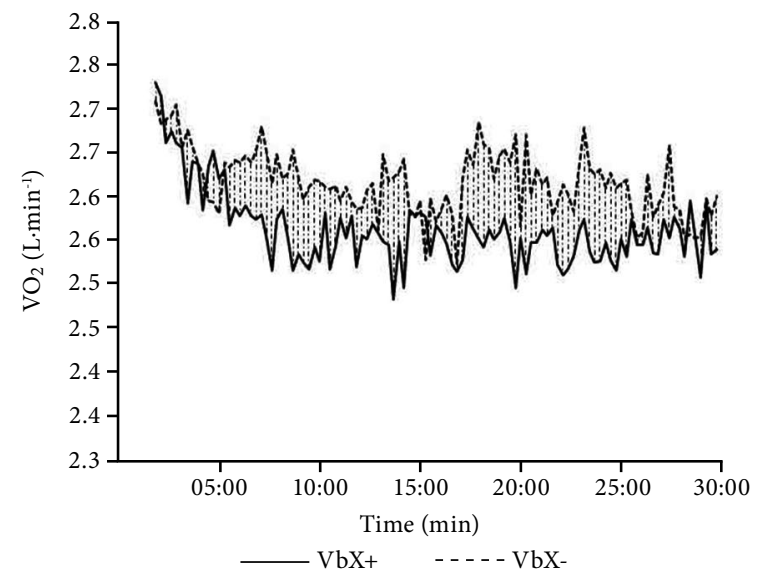

(b)

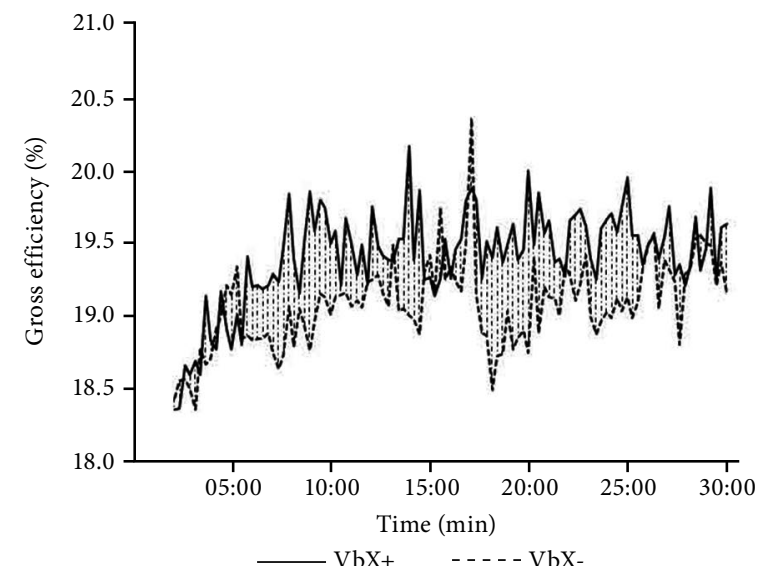

Figure 3. (a) Oxygen uptake and (b) gross efficiency differences of 30 min submaximal mountain bike trials. VbX+: With vibration; VbX-: Without vibration.

\begin{tabular}{|c|c|c|c|c|c|c|}
\hline \multicolumn{7}{|c|}{$\begin{array}{r}\text { TABLE } 2 \\
\text { Comparison of physiological and performance respons } \\
\text { with }(\mathrm{VbX}+) \text { and without }(\mathrm{Vb}\end{array}$} \\
\hline 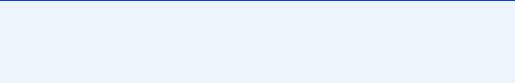 & \multicolumn{2}{|c|}{$\begin{array}{c}\mathrm{VbX}+ \\
\mathrm{IQR}\end{array}$} & \multicolumn{2}{|c|}{$\begin{array}{l}\text { VbX- } \\
\text { IQR }\end{array}$} & \multirow[b]{2}{*}{$p$} & \multirow{2}{*}{$\begin{array}{c}\text { ICC } \\
95 \% \text { CI }\end{array}$} \\
\hline & Median & Q1-Q3 & Median & Q1-Q3 & & \\
\hline $\mathrm{VO}_{2}\left(\mathrm{~mL} \cdot \mathrm{min}^{-1} \cdot \mathrm{kg}^{-1}\right)$ & 35.44 & $31.2-42.4$ & 36.68 & $31.53-42.53$ & 0.106 & 0.92 to 0.99 \\
\hline $\mathrm{VO}_{2}\left(\mathrm{~L} \cdot \mathrm{min}^{-1}\right)$ & 2.59 & $2.2-2.9$ & 2.63 & $2.2-3$ & 0.127 & 0.91 to 0.99 \\
\hline $\mathrm{VCO}_{2}\left(\mathrm{~L} \cdot \mathrm{min}^{-1}\right)$ & 2.4 & $1.9-2.6$ & 2.39 & $1.97-2.58$ & 0.578 & 0.71 to 0.98 \\
\hline Minute ventilation $\left(\mathrm{L} \cdot \mathrm{min}^{-1}\right)$ & 65.73 & $57.54-78.66$ & 67.55 & $57.54-78.66$ & 0.241 & 0.86 to 0.99 \\
\hline Respiratory exchange ratio & 0.87 & $0.85-0.89$ & 0.89 & $0.88-0.9$ & 0.578 & 0.71 to 0.98 \\
\hline Rating of perceived exertion (Borg scale) & 10 & $8-12$ & 10 & $8-11.5$ & 0.598 & 0.83 to 0.99 \\
\hline Heart rate (bpm) & 142 & $135-156$ & 140 & $136-146$ & 0.944 & 0.25 to 0.94 \\
\hline Gross efficiency $(\%)^{*}$ & 19.59 & $18.36-20.42$ & 19.02 & $18.02-20.09$ & 0.046 & 0.75 to 0.98 \\
\hline
\end{tabular}

\section{TABLE 3}

Comparison of gross efficiency differences over the 15-min intervals of 30-min submaximal mountain bike trials with $(\mathrm{VbX}+)$ and without (VbX-) vibration $(\mathrm{n}=8)$

\begin{tabular}{|c|c|c|c|c|c|c|c|c|}
\hline & \multirow[b]{2}{*}{ Bouts } & \multicolumn{2}{|c|}{$\begin{array}{c}\text { VbX+ } \\
\text { IQR }\end{array}$} & \multicolumn{2}{|c|}{$\begin{array}{l}\text { VbX- } \\
\text { IQR }\end{array}$} & \multirow[b]{2}{*}{$p$} & \multirow[b]{2}{*}{ ICC } & \multirow{2}{*}{$\begin{array}{c}\text { ICC } \\
95 \% \text { CI }\end{array}$} \\
\hline & & Median & Q1-Q3 & Median & Q1-Q3 & & & \\
\hline \multirow{2}{*}{ Gross efficiency (\%) } & First $15 \mathrm{~min}$ & 19.52 & $18.2-20.17$ & 19.67 & $18.5-20.69$ & 0.184 & 0.90 & 0.64 to 0.98 \\
\hline & Last $15 \min ^{*}$ & 18.85 & $17.93-19.92$ & 19.08 & $18.1-20.46$ & 0.023 & 0.95 & 0.80 to 0.99 \\
\hline
\end{tabular}

the $15-\mathrm{min}$ phase was $36.5 \pm 6.2 \mathrm{~mL} \cdot \mathrm{min}^{-1} \cdot \mathrm{kg}^{-1}$ under $\mathrm{VbX}+\left(0.7 \mathrm{~mL} \cdot \mathrm{min}^{-1} \cdot \mathrm{kg}^{-1}\right.$ difference from the mean), compared to $37.15 \pm 6.52 \mathrm{~mL} \cdot \mathrm{min}^{-1} \cdot \mathrm{kg}^{-1}$ under $\mathrm{VbX}-\left(0.01 \mathrm{~mL} \cdot \mathrm{min}^{-1} \cdot \mathrm{kg}^{-1}\right.$ difference from the mean). Moreover, the mean $\mathrm{HR}$ values were $144.9 \pm 14.2 \mathrm{bpm}$ and $144.5 \pm 15.5 \mathrm{bpm}$ under $\mathrm{VbX}+$ and $\mathrm{VbX}$ - conditions, respectively with the mean HR corresponding to $60 \%$ of $\mathrm{VO}_{2 \text { peak }}$ of $144.1 \pm 6.1 \mathrm{bpm}$. 


\section{DISCUSSION}

In this study, we evaluated the effects of GE\% and different physiological parameters of WBV training among off-road cyclists during submaximal mountain bike trials. Previous studies examined the effects of acute and long-term vibration applications on anaerobic and aerobic capacity. ${ }^{[15-17]}$ To date, a few studies have evaluated the effects of providing vibration during cycling performance on the cardiovascular performance and regulation of angiogenesis in mountain bike cyclists. ${ }^{[10,11]}$ Although the GE\% is a determinant performance factor in long-term aerobic endurance competitions, such as the ultra-marathon, the effects of vibration on GE\% have not been previously investigated in MTB. The main outcome of our study was to identify a significant increase in GE\% with the addition of intermittent vibration, compared to a normal cycling trial $(\mathrm{p}<0.05)$. However, the WBV training also caused a $1.5 \%$ lowering of the $\mathrm{VO}_{2}$ at a similar RPE value and same RER.

According to previous assumptions, increasing the cadence of cycling to an rpm of 80 to 120 was less economical than lower rpm cycling values. ${ }^{[18]}$ However, Lucia et al. ${ }^{[19]}$ further reported that a high cadence of 80 to $90 \mathrm{rpm}$ reduced activation of the knee extensor muscles (i.e., vastus lateralis and vastus medialis). However, it was shown with the activity of the knee flexors increasing at these relatively high pedal rates. ${ }^{[20,21]}$ Abbiss et al. ${ }^{[22]}$ also suggested that the downregulation of knee extensor muscles at higher pedal rates might be beneficial, as the negative force component of the knee extensors would be counterproductive to the force needed during the upstroke of the pedal. This negative force would result from and insufficient speed of the rear leg. Comparably, studies have reported mechanical efficiency to be increased by using a pulling pedaling pattern, although this pattern decreases the muscle efficiency. This decrease in muscle efficiency might be related to neuromuscular fatigue induced by the change in coordination during practice of this technical skill. ${ }^{[14,23,24]}$ Due to well-trained cyclists' overall pedaling technique and optimization of inertial effects, recovery of negative forces can be positively affected by vibration. Therefore, efficiency of knee flexor muscles may be increased by the $\mathrm{VbX}+$ condition.

The effect of the induced tonic vibration reflex may be closely related to the improvements in GE\%. This reflex potentiation is caused by the mechanical effects of vibration on the muscle spindles and is evident during both eccentric and concentric muscle contractions. The positive effects of vibration in improving neuromuscular performance are likely to be mediated via the effects of the tonic vibration reflex on postural control mechanisms. ${ }^{[4,8,25]} \mathrm{A}$ recent study of 18 adult participants performing static squats during WBV indicated a nearly $50 \%$ increase in the muscle activity, per body mass, contributed by the enhanced reflex muscle activity. ${ }^{[26]}$ The effects of vibration on muscle reflexes are likely to be different for slow and fast-twitch muscles. Muscles which have a dominance of slow-twitch fibers are more efficient at lower speeds of contraction, whereas fast-twitch muscles are more efficient at higher speeds of contraction. In cycling, this speed differentiation is lost, with both slow and fast-twitch muscles contracting together. ${ }^{[27,28]}$ As cycling time at a high cadence increases, muscle recruitment decreases and fatigue increases, resulting in an overall decrease in the recorded electromyography signal. ${ }^{[21,29]}$ As vibration enhances neuromuscular coordination, it is likely that fast-twitch muscles are selectively influenced by the positive effects of vibration. ${ }^{[30]}$ Thus, the enhanced neuromuscular synchronization induced by $\mathrm{VbX}+$ might have increased GE\% in our cycling protocol through its effect on fast-twitch muscles. Based on this finding, we can speculate that the effect of GE\% can be increased by VbX+ in combination with an optimal cadence.

The effects of vibration on performance may vary as a function of the exposure time. There is evidence that application of vibration for $>7$ min may decrease fitness parameters and activation of motor units. ${ }^{[31]}$ On the other hand, significant positive effects have been shown with a one-min exposure to vibration with benefits lasting up to $10 \mathrm{~min}$ after the application. ${ }^{[32]}$ Our findings obtained from an intermittent vibration application are consistent with the findings of Bosco et al. ${ }^{[32]}$

The effects of vibration on movement may be also due to, in part, the vibration-induced improvements in peripheral blood flow and a consequent increase in muscle viscosity with muscle resistance to change in length. A previous study examined the effects of WBV on peripheral blood vessel resistance, reporting an increased dilation of capillary vessels with vibration, contributing to an overall lowering of the peripheral resistance of the vasculature. ${ }^{[33]}$ Suhr et al. ${ }^{[11]}$ reported an increase in levels of some regulators that trigger angiogenesis, such as vascular endothelial growth factor with a short-duration bout of cycling. A significant increase in the blood flow speed has also been reported 
following an exercise performed on a vibrating plate (26 Hz, $3 \mathrm{~mm}$ amplitude). ${ }^{[34]}$ Therefore, vibrationinduced dilation of small diameter vessels would decrease peripheral resistance to blood flow, which may likely be mediated through an increase in endothelium-derived vasodilators, such as nitric oxide. ${ }^{[34,35]}$ Therefore, the effects of vibration of blood circulation has been supported by various studies, ${ }^{[36]}$ and our study confirmed these effects, indicating that vibration may have improved performance by increasing the blood flow in active muscles, eventually leading to increased GE values.

Surprisingly, the measured $\mathrm{VO}_{2}$ was lower under the condition of $\mathrm{VbX}+$, compared to $\mathrm{VbX}$ - and, therefore, the calculated GE\% was significantly higher in $\mathrm{VbX}+$. It is possible that the lowering of the $\mathrm{VO}_{2}$ could reflect the effects of vibration of blood circulation and, in particular, in the increase in nitric oxide. Indeed, it is known that L-arginine infusion, which is the active substance for nitric oxide formation, increases the glycolysis use, independent from insulin, as well as limits fat oxidation during aerobic exercises. Thus, increasing levels of nitric oxide could suppress cytochrome c oxidase and mitochondrial respiration. ${ }^{[37,38]}$ Therefore, the increase in GE values may be related to a rise in the anaerobic metabolism synchronized to fast-twitch muscle fibers and suppressed aerobic metabolism. This pathway would lead to a greater oxygen deficit and, therefore, to the decrease of approximately $1.5 \%$ in $\mathrm{VO}_{2}$ which we identified under the condition of $\mathrm{VbX}+$, compared to VbX-.

We conducted our study using a bike and trainer system that is commonly used by well-trained offroad cyclists in their training. These trainer systems do not provide a measure of external force in watts, but rather workloads are defined to correspond to specific ratios of physiological values, such as $\mathrm{VO}_{2}$ and $\mathrm{HR}$ obtained directly from the maximal incremental test. In our protocol, cyclists were asked to continue for $30 \mathrm{~min}$ at $60 \%$ of $\mathrm{VO}_{2 \text { peak. Indeed, }}$ $\mathrm{VbX}+$ and $\mathrm{VbX}$ - exercises were conducted at the work rates corresponded to 36.5 and $37.2 \mathrm{~mL} \cdot \mathrm{min}^{-1} \cdot \mathrm{kg}^{-1}$; $\mathrm{p}>0.05)$.

The major limitation of our study was the small sample size that may have led to lower statistical power. Application of rigid inclusion criteria and difficulty in finding mountain cyclists who are riding at such advanced and professional level. Thus, caution should be taken in generalizing our results to other populations. Further studies are needed to explore efficacy of vibration in other sport activities.
In conclusion, best of our knowledge, this is the first study to provide evidence of a positive benefit of intermittent acute vibration, using a 30 -min submaximal cycling trial, in improving GE\%. The effects of vibration exercises on efficiency should be evaluated for other vibration characteristics and protocols, as well over the recovery period following various exercises to help define optimal strategies for recovery in cyclists. In practical applications, this study may encourage trainers to provide intermittent vibration during cycling due to their possible positive effects and the natural role of vibration in off-road cycling.

\section{Acknowledgements}

We thank all the participants for allowing this research to take place.

\section{Declaration of conflicting interests}

The authors declared no conflicts of interest with respect to the authorship and/or publication of this article.

\section{Funding}

The authors received no financial support for the research and/or authorship of this article.

\section{REFERENCES}

1. Chidley JB, MacGregor AL, Martin C, Arthur CA, Macdonald JH. Characteristics explaining performance in downhill mountain biking. Int J Sports Physiol Perform 2015;10:183-90.

2. Aleman KB, Meyers MC. Mountain biking injuries in children and adolescents. Sports Med 2010;40:77-90.

3. Impellizzeri FM, Marcora SM. The physiology of mountain biking. Sports Med 2007;37:59-71.

4. Cardinale M, Wakeling J. Whole body vibration exercise: are vibrations good for you? Br J Sports Med 2005;39:585-9.

5. Adams JB, Edwards D, Serravite DH, Bedient AM, Huntsman E, Jacobs KA, et al. Optimal frequency, displacement, duration, and recovery patterns to maximize power output following acute whole-body vibration. J Strength Cond Res 2009;23:237-45.

6. Gortner L. Versorgungsstruktur in der Geburtsmedizin und Neonatologie-ImplikationenfürdieBehandlungsergebnisse? Klin Padiatr 2009;221:217-8.

7. Martin BJ, Park HS. Analysis of the tonic vibration reflex: influence of vibration variables on motor unit synchronization and fatigue. Eur J Appl Physiol Occup Physiol 1997;75:504-11.

8. Cardinale $\mathrm{M}$, Bosco $\mathrm{C}$. The use of vibration as an exercise intervention. Exerc Sport Sci Rev 2003;31:3-7.

9. Adamo DE, Martin BJ, Johnson PW. Vibration-induced muscle fatigue, a possible contribution to musculoskeletal injury. Eur J Appl Physiol 2002;88:134-40.

10. Billy S, Heinz K, De Marées M, Quarz D, Linville J, Matthias $\mathrm{H}$, et al Physiological and perceptual responses of adding vibration to cycling. Journal of Exercise Physiology Online 2009;12:40-6. 
11. Suhr F, Brixius K, de Marées M, Bölck B, Kleinöder $\mathrm{H}$, Achtzehn S, et al. Effects of short-term vibration and hypoxia during high-intensity cycling exercise on circulating levels of angiogenic regulators in humans. J Appl Physiol 2007;103:474-83.

12. Ettema G, Lorås HW. Efficiency in cycling: a review. Eur J Appl Physiol 2009;106:1-14.

13. Chavarren J, Calbet JA. Cycling efficiency and pedalling frequency in road cyclists. Eur J Appl Physiol Occup Physiol 1999;80:555-63.

14. Korff T, Romer LM, Mayhew I, Martin JC. Effect of pedaling technique on mechanical effectiveness and efficiency in cyclists. Med Sci Sports Exerc 2007;39:991-5.

15. Connolly LJ, Scott S, Mohr M, Ermidis G, Julian R, Bangsbo $\mathrm{J}$, et al. Effects of small-volume soccer and vibration training on body composition, aerobic fitness, and muscular $\mathrm{PCr}$ kinetics for inactive women aged 20-45. Journal of Sport and Health Science 2014;3:284-92.

16. Mueller SM, Aguayo D, Zuercher M, Fleischmann O, Boutellier U, Auer M, et al. High-intensity interval training with vibration as rest intervals attenuates fiber atrophy and prevents decreases in anaerobic performance. PLoS One 2015;10:e0116764.

17. Oosthuyse T, Viedge A, McVeigh J, Avidon I. Anaerobic power in road cyclists is improved after 10 weeks of wholebody vibration training. J Strength Cond Res 2013;27:485-94.

18. Chavarren J, Calbet JA. Cycling efficiency and pedalling frequency in road cyclists. Eur J Appl Physiol Occup Physiol 1999;80:555-63.

19. Lucia A, San Juan AF, Montilla M, CaNete S, Santalla A, Earnest C, et al. In professional road cyclists, low pedaling cadences are less efficient. Med Sci Sports Exerc 2004;36:1048-54.

20. MacIntosh BR, Neptune RR, Horton JF. Cadence, power, and muscle activation in cycle ergometry. Med Sci Sports Exerc 2000;32:1281-7.

21. Marsh AP, Martin PE. The relationship between cadence and lower extremity EMG in cyclists and noncyclists. Med Sci Sports Exerc 1995;27:217-25.

22. Abbiss, CR, Laursen PB, Peiffer JJ. Optimal cadence selection during cycling. International SportMed Journal 2009;10:1-15.

23. Mornieux G, Stapelfeldt B, Gollhofer A, Belli A. Effects of pedal type and pull-up action during cycling. Int J Sports Med 2008;29:817-22.

24. Sarre G, Lepers R, van Hoecke J. Stability of pedalling mechanics during a prolonged cycling exercise performed at different cadences. J Sports Sci 2005;23:693-701.
25. Fernandez-Rio J, Terrados N, Fernandez-Garcia B, Suman OE. Effects of vibration training on force production in female basketball players. J Strength Cond Res 2010;24:1373-80.

26. Lienhard K, Cabasson A, Meste O, Colson SS. sEMG during Whole-Body Vibration Contains Motion Artifacts and Reflex Activity. J Sports Sci Med 2015;14:54-61.

27. Heglund NC, Cavagna GA. Mechanical work, oxygen consumption, and efficiency in isolated frog and rat muscle. Am J Physiol 1987;253:C22-9.

28. Suzuki Y. Mechanical efficiency of fast- and slow-twitch muscle fibers in man during cycling. J Appl Physiol Respir Environ Exerc Physiol 1979;47:263-7.

29. Ahlquist LE, Bassett DR Jr, Sufit R, Nagle FJ, Thomas DP. The effect of pedaling frequency on glycogen depletion rates in type I and type II quadriceps muscle fibers during submaximal cycling exercise. Eur J Appl Physiol Occup Physiol 1992;65:360-4.

30. Kelly SB, Alvar BA, Black LE, Dodd DJ, Carothers KF, Brown LE. The effect of warm-up with whole-body vibration vs. cycle ergometry on isokinetic dynamometry. J Strength Cond Res 2010;24:3140-3.

31. Rittweger J, Beller G, Felsenberg D. Acute physiological effects of exhaustive whole-body vibration exercise in man. Clin Physiol 2000;20:134-42.

32. Bosco C, Iacovelli M, Tsarpela O, Cardinale M, Bonifazi M, Tihanyi J, et al. Hormonal responses to whole-body vibration in men. Eur J Appl Physiol 2000;81:449-54.

33. Mester J, Kleinöder H, Yue Z. Vibration training: benefits and risks. J Biomech 2006;39:1056-65.

34. Kerschan-Schindl K, Grampp S, Henk C, Resch H, Preisinger E, Fialka-Moser V, et al. Whole-body vibration exercise leads to alterations in muscle blood volume. Clin Physiol 2001;21:377-82.

35. Lohman EB, Petrofsky JS, Maloney-Hinds C, Betts-Schwab $\mathrm{H}$, Thorpe D. The effect of whole body vibration on lower extremity skin blood flow in normal subjects. Med Sci Monit 2007;13:CR71-6.

36. Issurin VB. Vibrations and their applications in sport: A review. J Sports Med Phys Fitness 2005;45:324-36.

37. Manukhina EB, Downey HF, Mallet RT. Role of nitric oxide in cardiovascular adaptation to intermittent hypoxia. Exp Biol Med (Maywood) 2006;231:343-65.

38. Reid M. Nitric oxide, reactive oxygen species, and skeletal muscle contraction. Medicine and Science in Sports and Exercise 2001;33:371-6. 